\title{
Efficiency of one-on-one play situations of Polish football players and their opponents during European Championships in relation to the playing area, current result and match
}

\author{
Andrzej Szwarc ${ }^{1 \mathrm{ABDE}}$, Krzysztof Kromke ${ }^{2 \mathrm{ABCDE}}$, Aleksander Stuła ${ }^{3 \mathrm{DE}}$, Bartosz Dolański1 ${ }^{1 \mathrm{DE}}$, Mateusz Sitek ${ }^{1 \mathrm{CDE}}$ \\ ${ }^{1}$ Gdansk University of Physical Education and Sport, Poland \\ ${ }^{2}$ St. Augustinusschule, Ettlinen, Germany \\ ${ }^{3}$ The Opole University of Technology, Opole, Poland
}

Authors' Contribution: A - Study design; B - Data collection; C - Statistical analysis; D - Manuscript Preparation; E - Funds Collection.

\begin{abstract}
Purpose: $\quad$ The aim of the study was to assess the effectiveness of players of the Polish national football team and their opponents in one-on-one situations (1-on-1) in 9 matches of the group stage of the three subsequent finals of the European Championships in the years 2008, 2012 and 2016.

Material: $\quad$ Audiovisual recordings of matches were analysed and game data were collected using the authors' original observation sheet. Activity, effectiveness and reliability of individual offensive and defensive actions were evaluated in terms of current match result, time elapsed and player position on the pitch. Efficiency of one-on-one play situations of 40 Polish players competing in group stages of Euro 2008-2012 was studied. The 20 of Polish National Team players taking part in this study were at the student's age (19-24 y) during championships and 6 of them were currently students or got a scientific degree.

Results: $\quad$ The study reveals that, on average, players engage in 2451 -on-1 duels in a single match and that the best teams demonstrate almost $60 \%$ effectiveness in individual defensive actions. While the efficiency of 1-on-1 situations is the highest in the middle stage of both parts of the game and in the defensive zone, it decreases with the lapse of time and in relation with the shift of action towards the opponent's goal.

Conclusions: Efficiency in 1-on-1 play determines success in competition and high reliability of individual defensive actions at the level close to $60 \%$ is the key differentiator of the winners' style of play.

Keywords: football, 1-on-1 play, efficiency, current match result, game time, player position.
\end{abstract}

Glossary: Zone of direct goal threat (DGT) - area defined by hypothetical lines running from the goal posts towards the corners of the penalty box extended for the distance of $25 \mathrm{~m}$ from the goal.

\section{Introduction}

In team sports, the final success is determined by both individual actions of the players as well as the collective handling of match situations, i.e., the gameplay skills. Gameplay skills are relative values determined each time by the player's dispositional and situational capacity of action. Dispositional capacity is the player's potential determined by the current state of mental qualities, effectiveness of cognitive and decision-making processes, level of motor skills and somatic characteristics. On the other hand, situational capability is established on the basis of circumstances in which a player acts; these include: the players' sports level, game rules, individual player objectives, competition importance, reactions of referees and spectators, weather conditions, current game result, elapsed time and player positions [1].

A proper evaluation of the efficiency of the players' actions has to include the situational variables which directly determine the complexity of the game situation.

\footnotetext{
(c) Andrzej Szwarc, Krzysztof Kromke, Aleksander Stuła,

Bartosz Dolański, Mateusz Sitek, 2020

doi:10.15561/20755279.2020.0308
}

The complexity of the game situation is directly affected by the time, player position and the tasks assigned to him or her [2, 3], skills of other players [3, 4] the game rules, place and current result [5-9]. It is worth noting that the indicator of a player's mastership is his ability to effectively cooperate and to perform various individual tasks in increasingly difficult conditions to reach a specific game purpose.

While the scientific research generally recognises the importance of individual action for the effectiveness of football play, the efforts of individual researchers are mainly focused on the search for model-based special performance indicators of players (key performance indicators) $[10,11]$, with the effectiveness of individual actions being treated as auxiliary to analysing other indicators of offensive and defensive play \{e.g., [12-14]\}. Reports on the evaluation of the effectiveness of the 1-on1 play, especially in terms of situational variables, are rare $[1,15,16]$.

One-on-one (1x1) play in attack is defined as a set of actions of the player in possession of the ball taken against one of his opponents in order to score a goal, create a goal-scoring situation, gain more playing space or retain the ball. On the other hand, the player's actions against the player with the ball aimed at intercepting the ball, interrupting the opponent's action or hindering the movement of the ball are defined as one-on-one play in 
defence [16].

Efficiency in 1-on1 play was measured in relation to:

a) activity (number of actions of a given kind performed by players of one team during the match),

b) efficiency (number of actions of a given kind performed to reach the objective),

c) reliability (the ratio of the number of effective actions and the number of all actions performed during the match) of offensive and defensive actions in 1-on-1 play situations in terms of the elapsed time and playing area.

The following research questions were raised:

1. What was the efficiency of individual offensive and defensive actions of the Polish national team players and their rivals in terms of the elapsed time, game result and players' area of operation?

2. What are the differences in the effectiveness of individual actions between the players of the Polish national team and the players of the rival teams during the European Championship tournament matches in 2008, 2012 and $2016 ?$

3. What changes have occurred in the efficiency of one-on-one play in the players of the Polish national team during the Euro 2008-2016?

Hypothesis. Based on latestest scientific research and knowledge about the final results of games played during Euro 2008-2016 by Polish national team at the beginning of our research we set a following hypothesis:

Polish national team significantly increased the activity, efficiency and reliability of 1-on-1 situations during group stages in Euro 2016 compared to tournaments organized in 2008 and 2012.

Purpose. The aim of the present study was to assess the effectiveness of play of the Polish national football team players and their opponents in the group stage matches of the Euro 2008, 2012 and 2016 tournaments in 1-on-1 situations in terms of the elapsed game, current game result and player's position.

\section{Material and Methods}

\section{Participants}

A total of 124 Polish football players' actions were assessed along with 123 actions on the part of their rivals (in the event of substitution, the achievements of the substituted player were summed up with the performance of the player entering the game). The total number of 54 (age $26.4 \pm 3.8$ y) male football players were appointed to Polish National Team for Euro 2008, 2012 and 2016, $20(37 \%)$ of them were at student's age (19-24 y) and 6 $(11,1 \%)$ were currently students or got a scientific degree. A sample of 44 Polish players appeared in analysed matches and $13(29.5 \%)$ of them were at student's age. Finally the efficiency of 40 Polish players in one-on-one situations was analysed. Goalkeepers were excluded from the study.

Procedure

The research method was observation, with the observation sheet as the research tool. Prior validation of the research tool has shown [16] that the level of intra- rater reliability of the expert's evaluation, expressed by the Kappa coefficient, was 0.96 , and for three experts, the inter-rater reliability was 0.93 . This meant that the Kappa coefficients were in the range of almost perfect agreement. The object of the analysis was the audiovisual recordings of the 9 matches played by the national team of Poland in the group stage of the final tournament of the European Championship in 2008, 2012 and 2016. Match data were recorded in the observation sheet on the basis of analysis of video recordings using freeze-frame. The field was divided into three 35-meter zones: defensive, central and offensive. The zone of direct goal threat (DGT) was also identified. Its boundaries were defined by hypothetical lines running from the goal posts towards the corners of the box. Outside the box, this area was extended for the distance of $25 \mathrm{~m}$ from the goal (Fig. 1).

In terms of the attack, we evaluated the effectiveness of the 1-on-1 play aimed at scoring a goal, creating a goal-scoring situation, gaining more playing space and keeping the ball. In terms of the defence, on the other hand, what was evaluated was the efficiency of actions against the player with the ball aimed at intercepting it or interrupting the rival's action. Actions of the goalkeeper in 1-on-1 situations within his own penalty area were not registered. Only activities recorded in the regular time were assessed. Individual actions performed by the players were divided into three categories: actions at tied (tie), positive and negative result. In order to compare the actions in these situations, an extrapolation was made; the results were averaged by dividing the obtained values of 1 -on-1 actions in each category by the number of minutes played in a given situation, and then multiplying the result by 90 .

\section{Statistical Analysis}

All statistical analyses were performed using the Statistica statistics package (version 10.0, Poland). The results were expressed as medians and standard deviations. Before using the single-factor ANOVA analysis of variance for single classification, the normality of distribution was checked using the Kolmogorov - Smirnov test, with Lilliefors test for correction. We compared three groups of variables of the results obtained by players in the matches of individual tournaments of the European Championship. In order to determine the significance of differences between groups of variables, the post-hoc NIR test was applied. We also used the Student's t-test for independent groups, with the prior assessment of normality of distribution using Shapiro-Wilk's test and homogeneity of variance using Brown and Forsyth test to determine the significance of the differences between the two groups of variables (the Polish team vs. rival team). The level of statistical significance of differences was set at $\mathrm{p} \leq 0.05$.

\section{Results}

The efficiency in the 1-on-1 play of the Polish team players and their rivals in terms of match time

In all of the 9 matches analysed (a total of 810 minutes of play) the result of the Polish national team 
was tied for 497 minutes, favourable for 168 minutes and unfavourable for 145 minutes. Two of analysed games have been won by Polish team, four matches ended up in a draw and three games have been lost by Polish team. Polish players scored 5 goals, 2 of them were scored in the first halves and 3 in the second halves. On the contrary the opponents scored 7 goals and 2 of them were scored in the first halves and 5 in the second parts.

During the analysed matches, the players engaged in 2208 1-on-1 duels: 1115 in the first 45 minutes of the game and 1093 in the second half. Polish national team players showed higher efficiency (1185 and 1023 respectively) and reliability in 1-on-1 play as compared with their rivals (respectively 53.7\% and 46.3\%), both during the first and the second halves of matches (reliability respectively: $53.4 \%, 53.9 \%$ and $46.6 \%, 46.0 \%$ ) (Tab. 1 ).

There was an increase in the reliability of the Polish team players in the first 45 minutes of play in matches of each of the tournaments played in 2008, 2012 and 2016 (respectively, 46.6\%, 53.2\% and 59.8\%). In the second halves of the matches the level of reliability decreased from Euro 2008 to Euro 2012, but the higest percenatege was observed in Euro 2016 (respectively: 54.1\%, 52.9\% and $54.9 \%$ ). It is worth noting (Tab. 2) that in the matches of the Euro 2008 Championship, the Polish football players were observed to have a lower reliability than their rivals in the first 45 minutes of the game (respectively $46.6 \%$ and $53.4 \%$ ), but already in the matches of the Euro 2012, their reliability increased by $6.6 \%$ in the first part of the match. By contrast, during the European Championship in 2016, they surpassed their opponents in terms of reliability both in the first 45 minutes of the game and the second halves (respectively: $59.8 \%$ and $40.2 \%$ and $54.9 \%$ and $45.1 \%$ ).

The values concerning the effectiveness of the actions of the Polish players and their opponents given in Table 1 show that the Polish national team players attained the highest $56.2 \%$ reliability of 1 -on-1 play in the period from 15 to 30 minutes of the game both for the first and the second halves of the studied matches. The reliability of their performance grew in the first two quarters to decrease in the last 15 minutes for both parts of the game. Naturally, the effectiveness of rival team in the studied intervals was reverse, i.e. the highest in the first and the last quarters of the first halves (respectively $47.6 \%$ and $48.6 \%$ ), and lowest in the middle 15 -minute intervals in both halves of the matches (respectively $43.8 \%$ and $44.0 \%$ ). However, the reliability of rivals in the 1-on-1 play was always lower than the reliability exhibited by the Polish players.

Further analysis of the achievements of the Polish team players and their opponents in the 15-minute periods shows (Tab. 1), that when attacking, the Polish players engaged in the highest number of 1-on-1 situations in the first and last quarters of the game (respectively: 194 and 201 duels), and achieved the highest $60.0 \%$ reliability of these actions between the 60th and 75 th minute of the second halves. In turn, their opponents most often attacked individually between the 30th and 45th minute of the game and in the first quarter of the second parts of the match (respectively: 202 and 200 duels), with the highest $50.5 \%$ reliability attained in the first quarters of the matches. On the other hand, the Polish team players attained higher defensive reliability in 1-on-1 play than their opponents in all 15-minute periods, with the highest reliability achieved in the last 15-minute parts of the game $59.7 \%$ (Tab. 1).

It is worth noting that in two out of the six 15-minute periods in each subsequent tournament, the Polish teams players showed higher reliability in 1-on-1 situations (between the 15th and 30th minute, respectively: $53.0 \%$, $55.3 \%, 60.0 \%$ and between the 60th and 75th minute, respectively: $49.5 \%, 58.1 \%, 59.5 \%$ ). The highest $64.1 \%$ reliability was reported for the Polish players between the 30th and 45th minute of the Euro 2016 matches (Tab. 1).

The data presented in Table 2 shows that the activity of the Polish players in the 1-on-1 play in the first 45 minutes of the game during the Euro 2012 was higher compared to the players of the national teams participating in the 2008 and 2016 tournaments $(\mathrm{p} \leq 0.01)$, while the efficiency and reliability of individual offensive and defensive performances was lower (respectively $\mathrm{p} \leq 0.001 \mathrm{p} \leq 0.01$ ). In addition, statistically significant differences were found between the efficiency and reliability in the 1-on-1 play of the participants of the Euro 2012 in the first 45 minutes of the game (also in terms of defence) and the results of the participants of the Euro 2016 (respectively: $p \leq 0.001$ and p $\leq 0.01$ ). In the Euro 2016 matches, the Polish players exhibited the highest efficiency (activity, efficiency, and reliability) in the offensive 1-on-1 play, which was significantly different from the achievements of the Polish players in the 2008 and 2012 tournaments (Tab. 2).

The findings in Table 2 show that in the European Championship in 2008, the players of the rival teams demonstrated higher reliability in case of 1-on-1 play in the first 45 minutes of the matches both in offensive and defensive actions $(\mathrm{p} \leq 0.05)$. However, in terms of individual defensive challenges, in the second halves of the game the Polish players acted with a statistically greater efficiency from their rivals. During the two subsequent 2012 and 2016 tournaments, the Polish players showed significantly higher efficiency and reliability in both offensive and defensive actions as compared to their rivals.

The efficiency in the 1-on-1 play of the Polish team players and their rivals in terms of position on the pitch

Data on the effectiveness of the 1-on-1 play of the Polish team players and their rivals in terms of pitch position are presented in Table 3 and Figure 1. The Polish football players engaged in 1153 duels in their half of the pitch $(52.2 \%)$ and in 1055 on the opponents' half (47.8\%). In total, the reliability of individual actions of rivals was lower than that of the Polish players both in their own half of the pitch (respectively: $49.1 \%$ and $56.2 \%$ ), and in the opponents' half (respectively: $43.8 \%$ and $50.9 \%$ ).

The detailed numerical characteristics of the 1-on-1 play efficiency in individual areas of the pitch revealed (Tab. 3, Fig.1) that the players of the opposing team engaged in the highest number of 
Table 1. The effectiveness of the actions of the Polish team players and their opponents in 15-minute periods in the studied matches of the Euro 2008-2016.

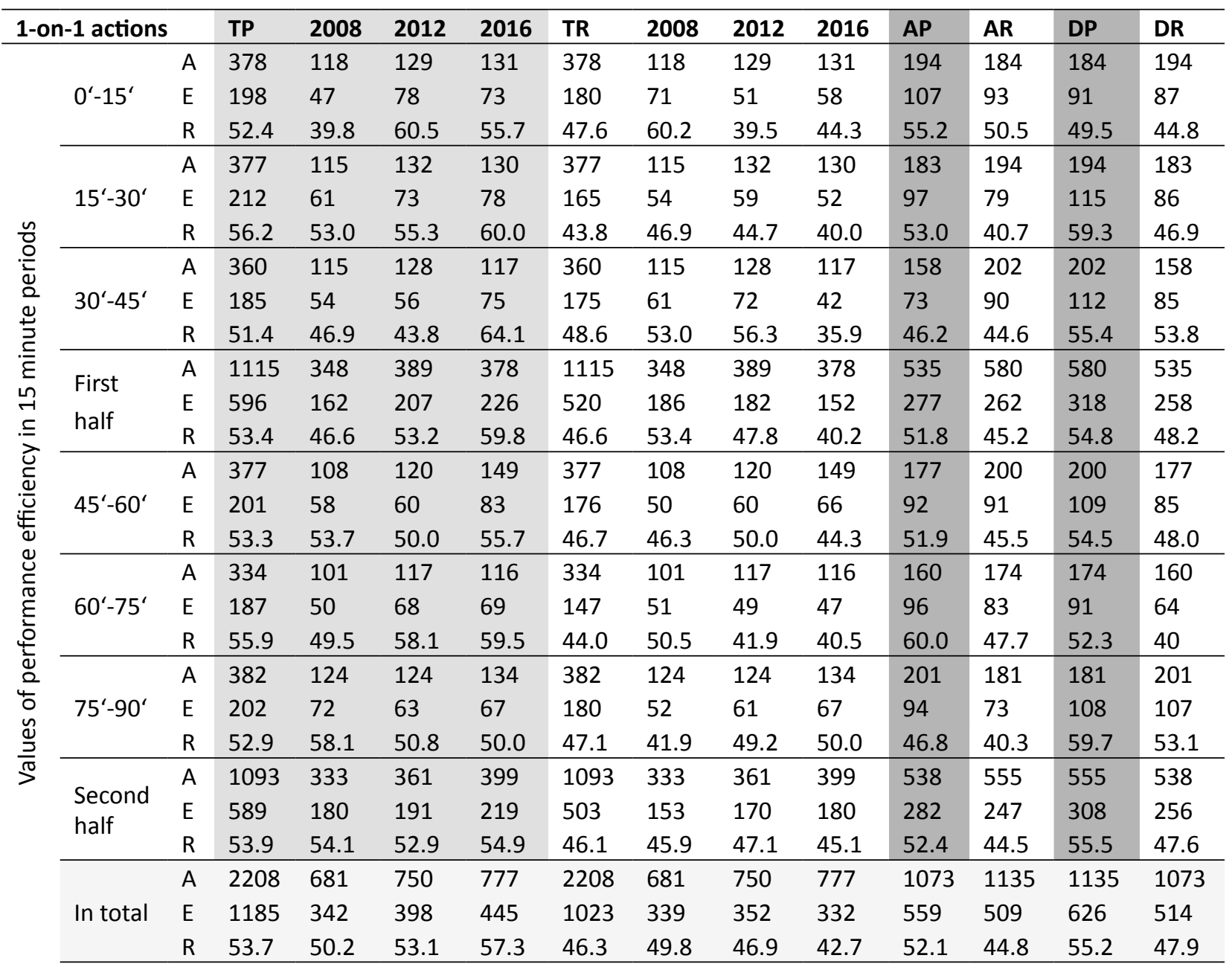

TP - In total Polish Teams; TR - In total Rival Teams; AP - In attack Polish Teams; AR - In attack Rival Teams; DP - In defence Polish Teams; DR - In defence Rival Teams; A - activity [number]; E - efficiency [number]; R - reliability [ \% ].

1-on-1 duels in the offensive zone in the Polish teams' halves, while the Polish players were more active from their opponents in the middle area of the field. The reliability of the 1-on-1 play both of Polish team players and their opponents decreased along with the shift from the defensive zone towards the opponent's goal; however, the Polish players were much more effective than their opponents in each of the studied areas of the pitch (Fig. 1). It is worth noting that the Polish national team players participating in each of the tournaments showed higher 1-on-1 play efficiency than in the previous tournament (Tab. 3 ).

The data presented in Table 4 shows that the Polish teams players exhibited higher and significantly different efficiency in the 1-on-1 play from his rivals in their own half of the field in each observed tournament $(\mathrm{p}<0.01)$. Moreover significantly higher efficiency was observed in the central area of the opponent's half for both Euro 2008 and Euro $2012(p<0.01)$. In turn, their opponents were more active than the Polish players in their own attack area $(\mathrm{p}<0.01)($ Tab. 4).
The efficiency of action in the 1-on-1 situations of the Polish team players and their rivals in terms of match result

The analysis of numerical data of the Polish teams and their opponents in terms of the current game result revealed (Tab. 5) that in all the distinguished categories (draw, win, lose) the players of the Polish teams exhibited higher reliability in the 1-on-1 play than their rivals; they were much more efficient than their rivals in periods of tied score (reliability respectively of $54.1 \%$ and $45.9 \%$ ), when winning the match (reliability respectively of $51.7 \%$ and $45.7 \%$ ) and also when losing (reliability respectively of $54.3 \%$ and $48.3 \%$ ).

It is worth noting (Tab. 5) that the opponent players were the most active when the score was tied (254 duels per match on average). The Polish players showed the highest $54.1 \%$ reliability, with defensive actions being more effective than the attack situations (respectively $55.5 \%$ and $52.6 \%$ ). In turn, the opposing teams exhibited $48.3 \%$ reliability of individual actions when the match result was unfavourable. 
Table 2. The efficiency of offensive and defensive play in the first and second halves of the match time of the Polish team players and their rivals in the Euro 2008, 2012 and 2016.

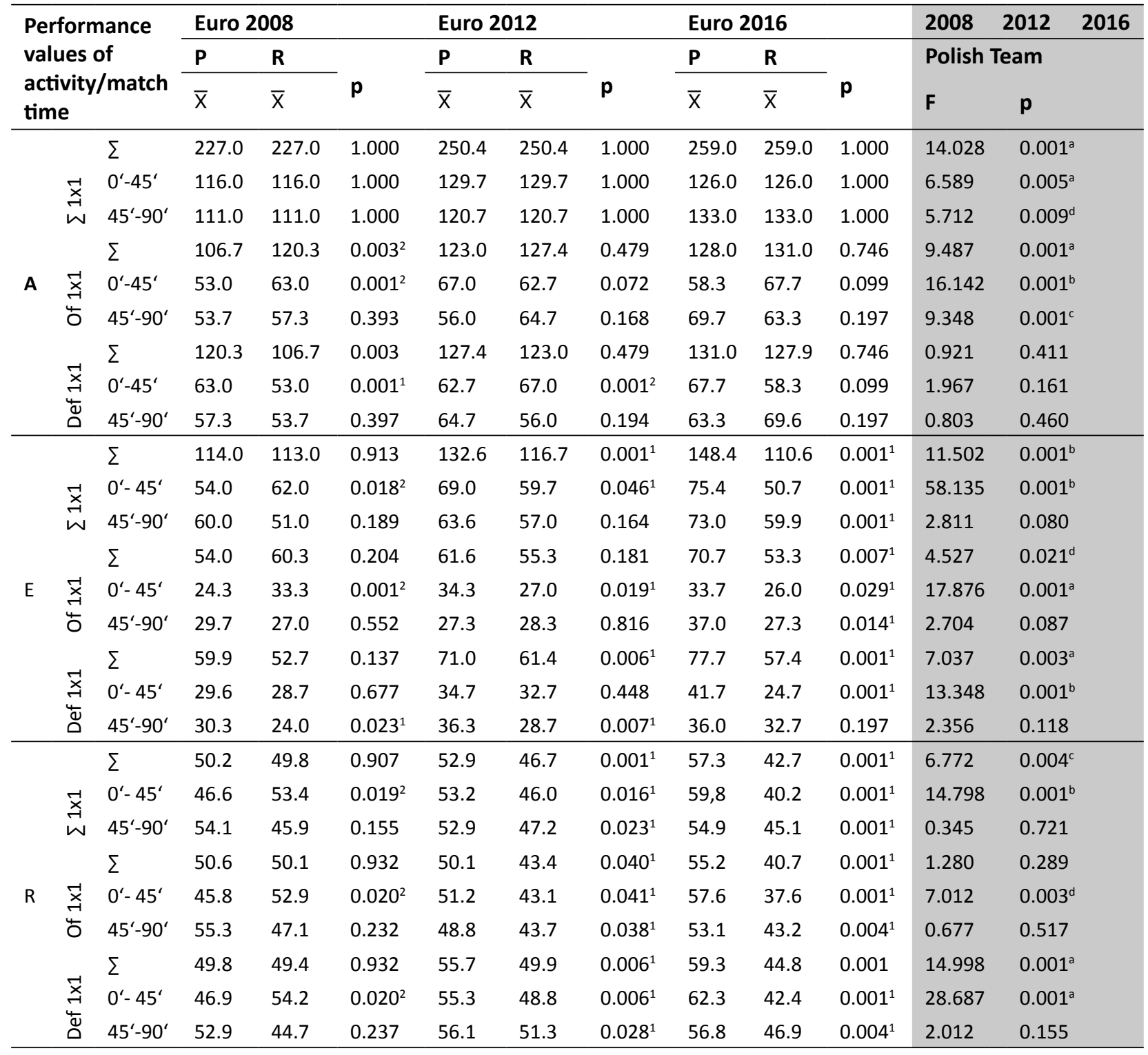

Activity [number]; E - Efficiency [number]; R - Reliability [\%]; $\mathrm{p}$ - significance level; $\mathrm{F}$ - value of variance analysis singlefactor test function; P - Polish teams; R - rival teams; 1-P > R; 2-P < R; a - 2008<2012 and 2016; b - 2008<2012 and 2016 and 2012<2016; c 2016>2008 and 2012; d 2008<2016.

In addition, the Polish teams players were more often engaged in defensive battles (an average of 126 in one match) and were more effective as compared to the players of the opposing teams (reliability respectively $55.2 \%$ and $47.9 \%$ ). On the other hand, their opponents showed higher activity in individual offensive actions (an average of 126 battles per match), but exhibited lower reliability (respectively $44.8 \%$ and $52.1 \%$ ). In case of favourable result, the Polish teams players and their opponents more readily engaged in offensive battles, while in case of unfavourable result they were more often involved in defensive battles (Tab. 5).

The results of the study presented in Table 5 demonstrate that in the Euro 2008 tournament matches the Polish players attained the highest reliability in individual offensive actions in cases of unfavourable result (56.9\%) while exhibiting the lowest reliability when attacking in case of favourable outcome $(40.3 \%)$. However, during the 2012 tournament matches they showed the highest reliability in defending $(61.8 \%)$ and the lowest when attacking in situations of favourable result (42.5\%). In turn, during the Euro 2016 matches they failed the least at individual defense actions (59.3\%), yet most often during offensive actions (53.9\%) with the tied score (Tab. 5).

\section{Discussion}

Success in football is largely decided by both the individual actions of the players and the skills to jointly implement the game objectives. The present work involved an assessment of the effectiveness of actions in 
Table 3. The efficiency in 1-on-1 action in individual zones of the Polish players and their rivals in the examined matches of the Euro 2008-2016.

\begin{tabular}{|c|c|c|c|c|c|c|c|c|c|c|c|c|c|}
\hline \multirow{2}{*}{\multicolumn{2}{|c|}{ Pitch area }} & \multicolumn{12}{|c|}{ Values of action efficiency } \\
\hline & & \multicolumn{3}{|l|}{ A } & \multicolumn{3}{|l|}{$\mathbf{E}$} & \multicolumn{3}{|l|}{$\mathbf{R}$} & \multicolumn{3}{|l|}{ Avg } \\
\hline Euro Tournament & & 2008 & 2012 & 2016 & 2008 & 2012 & 2016 & 2008 & 2012 & 2016 & 2008 & 2012 & 2016 \\
\hline \multirow{4}{*}{ In total } & $P$ & 2208 & & & 1185 & & & 53.7 & & & 245.3 & & \\
\hline & $\mathrm{R}$ & 2208 & & & 1023 & & & 46.3 & & & 245.3 & & \\
\hline & $P$ & 681 & 750 & 777 & 342 & 398 & 445 & 50.2 & 53.1 & 57.3 & 227.0 & 250.0 & 259.0 \\
\hline & $\mathrm{R}$ & 681 & 750 & 777 & 339 & 352 & 332 & 49.8 & 46.9 & 42.7 & 227.0 & 250.0 & 259.0 \\
\hline \multirow{4}{*}{$\begin{array}{l}\text { In total } \\
\text { Own half of the } \\
\text { field }\end{array}$} & $P$ & 1153 & & & 648 & & & 56.2 & & & 128.1 & & \\
\hline & $\mathrm{R}$ & 1055 & & & 518 & & & 49.1 & & & 117.2 & & \\
\hline & $P$ & 353 & 398 & 402 & 187 & 221 & 240 & 52.9 & 55.5 & 59.7 & 117.7 & 132.7 & 134.0 \\
\hline & $\mathrm{R}$ & 328 & 352 & 375 & 173 & 175 & 170 & 52.7 & 49.7 & 45.3 & 109.3 & 117.3 & 125.0 \\
\hline \multirow{4}{*}{ Defense zone } & $P$ & 653 & & & 381 & & & 58.3 & & & 72.6 & & \\
\hline & $\mathrm{R}$ & 510 & & & 266 & & & 52.2 & & & 56.7 & & \\
\hline & $P$ & 181 & 242 & 230 & 102 & 138 & 141 & 56.4 & 57.0 & 61.3 & 60.3 & 80.7 & 76.7 \\
\hline & $\mathrm{R}$ & 171 & 162 & 177 & 98 & 81 & 87 & 57.3 & 50.0 & 49.2 & 57.0 & 54.0 & 59.0 \\
\hline \multirow{4}{*}{$\begin{array}{l}\text { DGT } \\
\text { (Own half) }\end{array}$} & $P$ & 265 & & & 183 & & & 69.1 & & & 29.4 & & \\
\hline & $\mathrm{R}$ & 171 & & & 96 & & & 56.1 & & & 19.0 & & \\
\hline & $P$ & 77 & 97 & 91 & 54 & 68 & 61 & 70.1 & 70.1 & 67.0 & 25.7 & 32.3 & 30.3 \\
\hline & $\mathrm{R}$ & 45 & 66 & 60 & 29 & 34 & 33 & 64.4 & 51.5 & 55.0 & 15.0 & 22.0 & 20.0 \\
\hline \multirow{4}{*}{ Central zone } & $P$ & 500 & & & 267 & & & 53.4 & & & 55.6 & & \\
\hline & $\mathrm{R}$ & 545 & & & 252 & & & 46.2 & & & 60.6 & & \\
\hline & $P$ & 172 & 156 & 172 & 85 & 83 & 99 & 49.4 & 53.2 & 57.6 & 57.3 & 52.0 & 57.3 \\
\hline & $\mathrm{R}$ & 157 & 190 & 198 & 75 & 94 & 83 & 47.8 & 49.5 & 41.9 & 52.3 & 63.3 & 66.0 \\
\hline \multirow{4}{*}{$\begin{array}{l}\text { In total } \\
\text { Opponent's half }\end{array}$} & $P$ & 1055 & & & 537 & & & 50.9 & & & 117.2 & & \\
\hline & $\mathrm{R}$ & 1153 & & & 505 & & & 43.8 & & & 128.1 & & \\
\hline & $P$ & 328 & 352 & 375 & 155 & 177 & 205 & 47.3 & 50.3 & 54.7 & 109.3 & 117.3 & 125.0 \\
\hline & $\mathrm{R}$ & 353 & 398 & 402 & 166 & 177 & 162 & 47.0 & 44.5 & 40.3 & 117.7 & 132.7 & 134.0 \\
\hline \multirow{4}{*}{ Central zone } & $P$ & 545 & & & 293 & & & 53.8 & & & 60.6 & & \\
\hline & $\mathrm{R}$ & 500 & & & 233 & & & 46.6 & & & 55.6 & & \\
\hline & $P$ & 157 & 190 & 198 & 82 & 96 & 115 & 52.2 & 50.5 & 58.1 & 52.3 & 63.3 & 66.0 \\
\hline & $\mathrm{R}$ & 172 & 156 & 172 & 87 & 73 & 73 & 50.6 & 46.8 & 42.4 & 57.3 & 52.0 & 57.3 \\
\hline \multirow{4}{*}{ Attack zone } & $P$ & 510 & & & 244 & & & 47.8 & & & 56.7 & & \\
\hline & $\mathrm{R}$ & 653 & & & 272 & & & 41.7 & & & 72.6 & & \\
\hline & $P$ & 171 & 162 & 177 & 73 & 81 & 90 & 42.7 & 50.0 & 50.8 & 57.0 & 54.0 & 59.0 \\
\hline & $\mathrm{R}$ & 181 & 242 & 230 & 79 & 104 & 89 & 43.6 & 42.9 & 38.7 & 60.3 & 80.7 & 76.7 \\
\hline \multirow{4}{*}{$\begin{array}{l}\text { DGT } \\
\text { (Opponents half) }\end{array}$} & $P$ & 171 & & & 75 & & & 43.9 & & & 19.0 & & \\
\hline & $\mathrm{R}$ & 265 & & & 82 & & & 30.9 & & & 29.4 & & \\
\hline & $P$ & 45 & 66 & 60 & 16 & 32 & 27 & 35.6 & 48.5 & 45.0 & 15.0 & 22.0 & 20.0 \\
\hline & $\mathrm{R}$ & 77 & 97 & 91 & 23 & 29 & 30 & 29.9 & 29.9 & 32.9 & 25.7 & 32.3 & 30.3 \\
\hline
\end{tabular}

DGT - area of direct goal threat; P - Polish team players, R - Opponent players; A - Activity [number]; E - Efficiency [number]; R - Reliability [\%]; Avg - The average number of actions in the game [number] 
Table 4. The efficiency of the 1-on-1 play by the Polish national teams players and their rivals in the various areas of the field during the European Championship in 2008, 2012 and 2016.

\begin{tabular}{|c|c|c|c|c|c|c|c|c|c|c|}
\hline \multirow{3}{*}{\multicolumn{2}{|c|}{$\begin{array}{l}\text { Efficiency values of action/area } \\
\text { of the field }\end{array}$}} & \multicolumn{3}{|c|}{ Euro 2008} & \multicolumn{3}{|c|}{ Euro 2012} & \multicolumn{2}{|c|}{ Euro 2016} & \multirow{3}{*}{$\mathbf{p}$} \\
\hline & & $\mathbf{P}$ & $\mathbf{R}$ & \multirow[b]{2}{*}{$\mathbf{p}$} & $\mathbf{P}$ & $\mathbf{R}$ & \multirow{2}{*}{$\mathbf{P}$} & $\mathbf{P}$ & $\mathbf{R}$ & \\
\hline & & $\bar{x}$ & $\bar{x}$ & & $\bar{x}$ & $\bar{x}$ & & $\bar{x}$ & $\bar{x}$ & \\
\hline \multirow{3}{*}{ In total - own half } & $A$ & 133.3 & 121.1 & 0.087 & 126.0 & 117.2 & 0.218 & 125.3 & 113.3 & $0.037^{1}$ \\
\hline & $E$ & 77.0 & 55.0 & $0.001^{1}$ & 71.3 & 57.2 & $0.005^{1}$ & 68.3 & 55.5 & $0.002^{1}$ \\
\hline & $\mathrm{R}$ & 57.8 & 45.9 & $0.001^{1}$ & 55.9 & 49.6 & $0.012^{1}$ & 54.3 & 49.2 & $0.025^{1}$ \\
\hline \multirow{3}{*}{ Defense zone } & $A$ & 78.9 & 56.0 & $0.001^{1}$ & 68.5 & 58.0 & 0.156 & 70.5 & 55.5 & $0.007^{1}$ \\
\hline & $E$ & 46.5 & 28.0 & $0.002^{1}$ & 40.5 & 30.8 & 0.059 & 40.0 & 29.8 & $0.009^{1}$ \\
\hline & $\mathrm{R}$ & 59.0 & 50.7 & $0.003^{1}$ & 57.4 & 54.4 & 0.329 & 56.0 & 52.7 & 0.199 \\
\hline \multirow{3}{*}{$\begin{array}{l}\text { DGT } \\
\text { (Own half) }\end{array}$} & $A$ & 31.3 & 21.0 & $0.001^{1}$ & 28.0 & 17.5 & $0.001^{1}$ & 29.0 & 18.5 & $0.001^{1}$ \\
\hline & $E$ & 21.5 & 11.2 & $0.001^{1}$ & 19.2 & 10.3 & $0.001^{1}$ & 20.3 & 10.5 & $0.001^{1}$ \\
\hline & $\mathrm{R}$ & 67.1 & 54.9 & $0.001^{1}$ & 66.5 & 61.0 & 0.218 & 69.2 & 57.7 & $0.003^{1}$ \\
\hline \multirow{3}{*}{$\begin{array}{l}\text { Central zone } \\
\text { (Own half) }\end{array}$} & $A$ & 54.7 & 64.7 & $0.001^{2}$ & 57.3 & 59.2 & 0.560 & 54.7 & 57.8 & 0.319 \\
\hline & $E$ & 30.3 & 29.5 & 0.618 & 30.7 & 26.3 & $0.018^{1}$ & 28.0 & 28.3 & 0.934 \\
\hline & $\mathrm{R}$ & 55.4 & 45.4 & $0.001^{1}$ & 53.3 & 45.3 & $0.001^{1}$ & 51.2 & 48.7 & 0.266 \\
\hline \multirow{3}{*}{$\begin{array}{l}\text { Central zone } \\
\text { (Own half + Opponent's } \\
\text { half) }\end{array}$} & $A$ & 119.3 & 119.3 & 1.000 & 116.3 & 116.5 & 0.972 & 112.3 & 112.5 & 0.967 \\
\hline & $E$ & 65.5 & 53.8 & $0.001^{1}$ & 63.5 & 53.0 & $0.004^{1}$ & 57.7 & 54.6 & 0.337 \\
\hline & $\mathrm{R}$ & 54.8 & 45.2 & $0.001^{1}$ & 53.0 & 46.1 & $0.001^{1}$ & 50.9 & 49.0 & 0.302 \\
\hline \multirow{3}{*}{ In total - opponent's half } & $A$ & 121.2 & 133.2 & 0.087 & 117.2 & 125.8 & 0.221 & 113.3 & 125.1 & $0.041^{1}$ \\
\hline & $E$ & 63.6 & 56.5 & 0.107 & 60.0 & 54.7 & 0.232 & 55.3 & 57.2 & 0.566 \\
\hline & $\mathrm{R}$ & 52.2 & 42.2 & $0.001^{1}$ & 50.5 & 44.2 & $0.013^{1}$ & 48.8 & 45.9 & 0.165 \\
\hline \multirow{3}{*}{$\begin{array}{l}\text { Central area (Opponent's } \\
\text { half) }\end{array}$} & $A$ & 64.6 & 54.7 & $0.001^{1}$ & 59.2 & 57.3 & 0.560 & 57.8 & 54.7 & 0.317 \\
\hline & $E$ & 35.2 & 24.3 & $0.001^{1}$ & 32.8 & 26.7 & $0.011^{1}$ & 29.7 & 26.7 & 0.142 \\
\hline & $\mathrm{R}$ & 54.5 & 44.6 & $0.001^{1}$ & 54.7 & 46.1 & $0.001^{1}$ & 51.2 & 48.8 & 0.266 \\
\hline \multirow{3}{*}{ Attack zone } & $A$ & 56.0 & 78.8 & $0.005^{2}$ & 58.0 & 68.0 & 0.156 & 55.5 & 70.6 & $0.007^{2}$ \\
\hline & $E$ & 28.5 & 32.2 & 0.354 & 27.1 & 28.0 & 0.814 & 25.6 & 30.5 & $0.031^{2}$ \\
\hline & $\mathrm{R}$ & 49.3 & 40.9 & $0.002^{1}$ & 45.6 & 42.5 & 0.329 & 47.2 & 43.8 & 0.189 \\
\hline \multirow{3}{*}{$\begin{array}{l}\text { DGT } \\
\text { (Opponent's half) }\end{array}$} & $A$ & 21.0 & 31.3 & $0.001^{2}$ & 17.5 & 28.0 & $0.001^{2}$ & 18.5 & 29.0 & $0.001^{2}$ \\
\hline & $\mathrm{E}$ & 9.8 & 9.8 & 1.000 & 7.2 & 8.8 & 0.238 & 8.0 & 8.7 & 0.482 \\
\hline & $\mathrm{R}$ & 45.0 & 32.9 & $0.001^{1}$ & 38.9 & 33.4 & 0.219 & 42.3 & 30.7 & $0.003^{1}$ \\
\hline
\end{tabular}

p-significance level; $A$ - activity, $E$ - efficiency, $R$ - reliability; DGT - area of direct goal threat; $P$ - Polish team $R$ - rival team; ${ }^{1} P->R ;{ }^{2} P<R$;

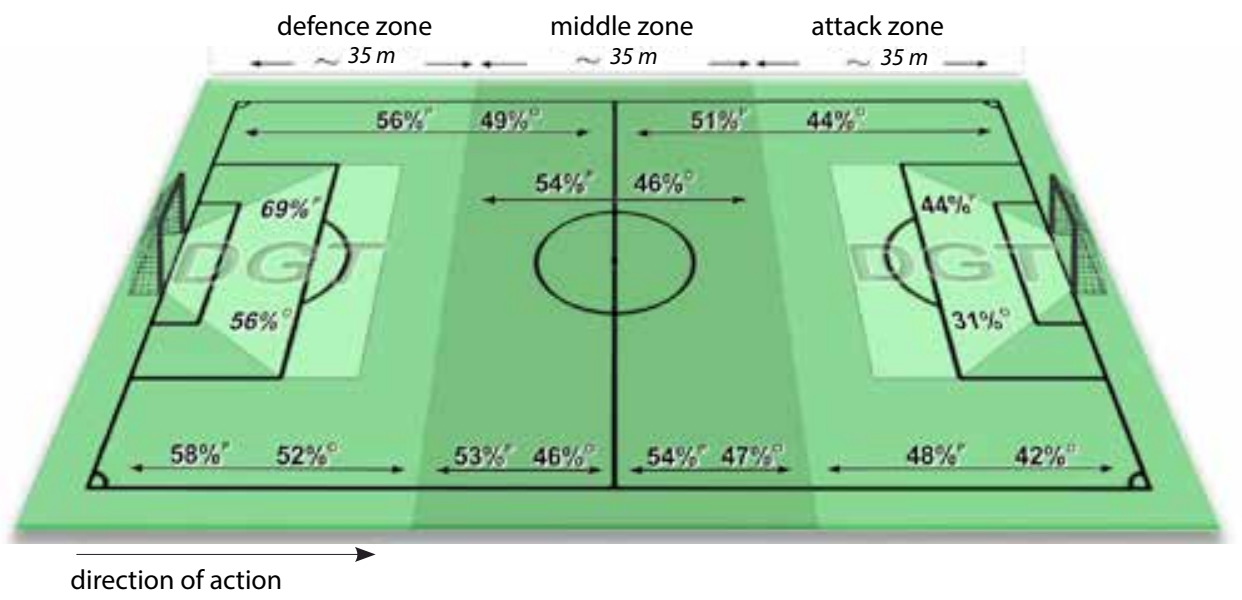

$P$ - team Poland, O-Opponents

Figure 1. Reliability in 1-on-1 situations in each zone of the field by the Polish teams players and their rivals in the analysed matches of Euro 2008-2016. 
Table 5. Efficiency in 1-on-1 situations of the Polish team players and their rivals in terms of current match result.

\begin{tabular}{|c|c|c|c|c|c|c|c|c|c|c|c|c|c|}
\hline \multirow{2}{*}{\multicolumn{2}{|c|}{ Match course }} & \multicolumn{12}{|c|}{ Values of action efficiency } \\
\hline & & \multicolumn{3}{|l|}{ A } & \multicolumn{3}{|l|}{$\mathbf{E}$} & \multicolumn{3}{|l|}{$\mathbf{R}$} & \multicolumn{3}{|l|}{ Avg } \\
\hline Euro Tourna & & 2008 & 2012 & 2016 & 2008 & 2012 & 2016 & 2008 & 2012 & 2016 & 2008 & 2012 & 2016 \\
\hline \multirow{2}{*}{ In total } & $P$ & 2208 & & & 1185 & & & 53.7 & & & 245.3 & & \\
\hline & $\mathrm{R}$ & 2208 & & & 1023 & & & 46.3 & & & 245.3 & & \\
\hline \multirow{4}{*}{ In attack } & $P$ & 1073 & & & 559 & & & 52.1 & & & 119.2 & & \\
\hline & $\mathrm{R}$ & 1135 & & & 509 & & & 44.8 & & & 126.1 & & \\
\hline & $P$ & 320 & 369 & 384 & 162 & 185 & 212 & 50.6 & 50.1 & 55.2 & 106.7 & 123.0 & 128.0 \\
\hline & $\mathrm{R}$ & 361 & 381 & 393 & 181 & 168 & 160 & 50.1 & 44.1 & 40.7 & 120.3 & 127.0 & 131.0 \\
\hline \multirow{4}{*}{ In defence } & $P$ & 1135 & & & 626 & & & 55.2 & & & 126.1 & & \\
\hline & $\mathrm{R}$ & 1073 & & & 514 & & & 47.9 & & & 119.2 & & \\
\hline & $P$ & 361 & 381 & 393 & 180 & 213 & 233 & 49.9 & 55.9 & 59.3 & 120.3 & 127.0 & 131.0 \\
\hline & $\mathrm{R}$ & 320 & 369 & 384 & 158 & 184 & 172 & 49.4 & 49.9 & 44.8 & 106.7 & 123.0 & 128.0 \\
\hline \multicolumn{14}{|c|}{ 1-on-1 actions with tied score (draw) } \\
\hline \multirow{2}{*}{ In total } & $\mathrm{P}$ & 1400 & & & 758 & & & 54.1 & & & $253.5^{*}$ & & \\
\hline & $\mathrm{R}$ & 1400 & & & 642 & & & 45.9 & & & $253.5^{*}$ & & \\
\hline \multirow{4}{*}{ In attack } & $P$ & 667 & & & 351 & & & 52.6 & & & $120.8^{*}$ & & \\
\hline & $\mathrm{R}$ & 733 & & & 326 & & & 44.5 & & & $132.7^{*}$ & & \\
\hline & $P$ & 130 & 272 & 265 & 65 & 143 & 143 & 50.0 & 52.6 & 53.9 & $112.5^{*}$ & $123.3^{*}$ & $122.3^{*}$ \\
\hline & $\mathrm{R}$ & 158 & 284 & 291 & 83 & 128 & 115 & 52.5 & 45.1 & 39.5 & $136.7^{*}$ & 129.1* & $134.1^{*}$ \\
\hline \multirow{4}{*}{ In defence } & $P$ & 733 & & & 407 & & & 55.5 & & & $132.7^{*}$ & & \\
\hline & $\mathrm{R}$ & 667 & & & 316 & & & 47.4 & & & $120.8^{*}$ & & \\
\hline & $P$ & 158 & 284 & 291 & 75 & 156 & 176 & 47.5 & 54.9 & 60.5 & $136.7^{*}$ & 129.1* & $134.1^{*}$ \\
\hline & $\mathrm{R}$ & 139 & 272 & 265 & 65 & 129 & 122 & 46.8 & 47.4 & 46.0 & $112.5^{*}$ & $123.3^{*}$ & $122.3^{*}$ \\
\hline \multicolumn{14}{|c|}{ 1-on-1 actions at favourable result } \\
\hline \multirow{2}{*}{ In total } & $\mathrm{P}$ & 445 & & & 230 & & & 51.7 & & & $238.4^{*}$ & & \\
\hline & $\mathrm{R}$ & 363 & & & 166 & & & 45.7 & & & $225.3^{*}$ & & \\
\hline \multirow{4}{*}{ In attack } & $P$ & 226 & & & 113 & & & 50.0 & & & $121.1^{*}$ & & \\
\hline & $\mathrm{R}$ & 183 & & & 81 & & & 44.3 & & & 113.6* & & \\
\hline & $P$ & 67 & 40 & 119 & 27 & 17 & 69 & 40.3 & 42.5 & 57.9 & $102.2^{*}$ & 105.9* & $142.8^{*}$ \\
\hline & $\mathrm{R}$ & 128 & 55 & --- & 60 & 21 & --- & 46.9 & 38.2 & --- & $107.7^{*}$ & $130.3 *$ & --- \\
\hline \multirow{4}{*}{ In defence } & $P$ & 219 & & & 117 & & & 53.4 & & & $117.3^{*}$ & & \\
\hline & $\mathrm{R}$ & 180 & & & 85 & & & 47.2 & & & $111.7^{*}$ & & \\
\hline & $P$ & 75 & 42 & 102 & 37 & 23 & 57 & 49.3 & 54.8 & 55.9 & $114.4^{*}$ & $111.2^{*}$ & $122.4^{*}$ \\
\hline & $\mathrm{R}$ & 123 & 57 & --- & 53 & 32 & --- & 43.1 & 56.1 & --- & $103.5^{*}$ & $135.0^{*}$ & --- \\
\hline \multicolumn{14}{|c|}{ 1-on-1 actions at unfavourable score } \\
\hline \multirow{2}{*}{ In total } & $P$ & 363 & & & 197 & & & 54.3 & & & $225.3^{*}$ & & \\
\hline & $\mathrm{R}$ & 445 & & & 215 & & & 48.3 & & & $238.4^{*}$ & & \\
\hline & $P$ & 180 & & & 95 & & & 52.8 & & & $111.7^{*}$ & & \\
\hline In attack & $\mathrm{R}$ & 219 & & & 102 & & & 46.6 & & & 117.3* & & \\
\hline In altack & $P$ & 123 & 57 & --- & 70 & 25 & --- & 56.9 & 43.9 & --- & $103.5^{*}$ & 135.0* & --- \\
\hline & $\mathrm{R}$ & 75 & 42 & 102 & 38 & 19 & 45 & 50.7 & 45.2 & 44.1 & $114.4^{*}$ & $111.2^{*}$ & $122.4^{*}$ \\
\hline & $P$ & 183 & & & 102 & & & 55.7 & & & 113.6* & & \\
\hline & $\mathrm{R}$ & 226 & & & 113 & & & 50.0 & & & 121.1* & & \\
\hline In deтеnce & $P$ & 128 & 55 & --- & 68 & 34 & --- & 53.1 & 61.8 & --- & $107.7^{*}$ & $130.3^{*}$ & --- \\
\hline & $\mathrm{R}$ & 67 & 40 & 119 & 40 & 23 & 50 & 59.7 & 57.5 & 42.0 & $102.2^{*}$ & $105.9 *$ & $142.8^{*}$ \\
\hline
\end{tabular}

$\mathrm{P}$ - team Poland; R - rival team; * results after extrapolation; A - Activity [number]; E - Efficiency [number]; R Reliability [\%]; Avg - The average number of actions in the game [number] 
1-on-1 situations of a total of 124 Polish teams players and 123 of their opponents in the group stage matches of the final tournaments of the European football championship played in 2008, 2012 and 2016.

Our studies show that the examined players engaged in an average of 245 one against one battle per match. They exhibited similar activity in the first and the second halves of the matches, while the Polish national team players were much more efficient than their rivals in both the first (reliability respectively at $53.4 \%$ and $46.6 \%$ ) and the second halves of the game (reliability respectively at $53.9 \%$ and $46.0 \%$ ). It should be noted that the Polish teams showed higher effectiveness (activity, efficiency and reliability) in the games of each of the subsequent European championships, which was significant to the extent that during the Euro 2016 they already exceeded the reliability of the actions of their opponents by nearly $15 \%$ (respectively $57.3 \%$ and $42.7 \%$ ).

Our results do not differ from the results presented in other studies. Dellal et al. [6] and Szwarc et al. [1] showed that players with the highest skills competing in the final tournaments of the World and European Championships and the best football leagues perform an average of 230 1-on-1 duels with reliability greater than $50 \%$. What is more, the higher reliability in 1 -on- 1 battles is observed, the higher the end result of the team in a given tournament. For instance, Loy [17] demonstrated $55 \%$ reliability in the 1-on-1 play of the German football players - the champions of the World Cup in 1990, while Szwarc et al. [1] showed 56\% reliability of battles that the Spanish players engaged in during all the matches of the European and World tournaments in 2008 and 2010 which they eventually won. Similarly, the analysed Polish players participating in the Euro 2008 (ending only 3rd in the group stage) showed only $50.2 \%$ reliability in 1-on-1 duels, while during the matches of the 2016 tournament (in which they advanced to the quarter-finals) they reached $57.3 \%$ reliability in 1-on-1 play.

The examination of the effectiveness of actions in 1-on-1 play in 15-minute periods showed that when attacking, the Polish players engaged most frequently in 1-on-1 play in the first and the last quarters of the game, while reaching the highest reliability between the 15 th and 30 th minute of both parts of the game. On the other hand, they attained higher defensive reliability in 1-on-1 play than their opponents in all 15-minute periods, with the highest reliability achieved in the last 15-minute parts of the game. Thus, we confirmed previous observations, in particular by Armatas et al. [18], Njororai [19] and Harper et al. [20], and Zhao \& Zhang [21], who suggest that teams with the highest playing abilities are most active in the initial and final phases of both parts of the game, because it is then when they want to change the result or keep the existing score. Teams ranked higher attain high reliability in defensive actions [2, 9, 22-24], also in 1 -on-1 play $[1,16]$. In addition, the observed higher and significantly different reliability in the subsequent Euro 2008, 2012 and 2016 tournaments in 1-on-1 play by the Polish players is also evidence of increasingly higher football skills of the Polish football teams participating in the finals, which finds corroboration in the official FIFA rankings. Thus, it seems well justified to claim that players with higher playing skills achieve generally higher efficiency in individual actions as compared to their rivals, with very high reliability in the defensive battles being the key differentiator of the winners. It also needs to be added that, following our previous research [1], an exception to this rule were the Spanish national teams participating in the 2008 and 2012 European tournaments and the 2010 World Cup, who also showed very high reliability in the individual offensive actions. The Spanish national teams of these years created a unique style of play, unattainable for other national teams.

Our results on efficiency of 1-on-1 play in terms of game area showed that the Polish national team players demonstrated higher and significantly different reliability in 1-on-1 play from their rivals in all areas of the field, especially in their half and in the central area of the pitch. In turn, their opponents were much more active in their own offensive area. Thus, we confirm the findings of earlier studies by Collet [25], O'Donoghue [26], Szwarc et al. [16]. The researchers proved that the activity in both individual actions as well as in joint ball possession in the opponent's defensive area is not a significant determinant of the winners' effective play. What is actually crucial is the reliability of defensive actions, also the individual ones [16], and the activity and efficiency of actions in the central area of the field $[27,28]$, understood as the immediate desire to intercept the ball and create a goalscoring situation is the common characteristic of the playing style of top-level teams [4, 29, 30]. However, regardless of the level of the teams' sports skills, the reliability of individual offensive actions decreases as it shifts towards the area of the opponents' defense.

The results of own research concerning the effectiveness of the actions in the event of 1-on-1 play in terms of the current match result showed that the investigated teams competed more than 3 times longer in the situations of tied score as compared to periods of favourable and unfavourable result. We demonstrated that the Polish team players were the most active in 1-on-1 play situations when the result was tied. In addition, they exhibited a higher reliability (more than $50 \%$ ) in cases of favourable, unfavourable and tied score both in attack and defense as compared to their opponents.

In turn, Szwarc and Dolański [31] showed that the individual and team activity of the players competing in the semifinal and the final matches of the 2006 World Cup and the 2008 European Championship is statistically significantly higher in situations of unfavourable score than in case of favourable result; however, the situations of play at tied score were not analysed. Their observations were confirmed by Lago-Peñas and Gómez-López [32], who studied ball possession of the English Premier League players in the season 2012/2013, proving that it decreases in teams that are in situation of favourable result (1 goal lead). 


\section{Conclusions}

Polish national team players participating in the Euro 2012 and 2016 tournaments showed similar high activity in 1-on-1 actions which was much higher than in case of the Euro 2008, while the activity in offensive situations exhibited by the players during the 2016 tournament in case of favourable result may point to high individual skills of these players. These results proved our hypothesis that during Euro 2016 Polish players achieved higher numbers in terms of activity in 1-on-1 situations compared to 2008 and 2012 tournaments. However this findings may be related with time spent in a favourable result in particular tournaments. Moreover in most cases Polish national teams achived higher efficiency and reliability depending on the elapsed time, current result and playing area during Euro 2016. Despite the fact that the frequency of actions in the 1-on-1 play varies depending on the current match result, the suggestion that the play in situations with neutral, favourable or unfavourable score determines the style of play of teams is unfounded. In summary, the analysis of results and the overview of the available literature on the subject demonstrate that an effective 1-on-1 play determines success in competition, and high reliability of individual defensive actions at the level close to $60 \%$ is the key differentiator of the winners' style of play. Furthermore another important factor which must be considered interpreting our results is significant number of players at the student's age in group of appointed players. The group of players at the age of 19-24 represented nearly half (45.5\%) of all Polish players participating in Euro tournaments. Moreover six of them have been studied or got a scientific degree during their professional career. A significant number of players at the student's age competing at international level is an important indication for coaches of academic teams. Our conlusions should be helpful for selection process and team recruitment both at professional and academic level. Methods of analyzing one-on-one situations presented in our research may be used as an objective assement tool for football player's actions and be the source of further conlusions leading to new solutions in football training. Highlighting the fact that group at the student's age were a significant part of players competing at the highest level an application of one-on-one play evaluation should be considered in pedagogical study programmmes designing for future physical education teachers and coaches.

\section{Highlights}

- Players engage on average in 245 1-on-1 situations per match

- Polish national team during the Euro 2016 exceeded the reliability of the actions of their opponents by nearly $15 \%$

- The Polish national team players demonstrated higher and significantly different reliability in 1-on-1 play from their rivals in all areas of the field

- The Polish team players were the most active in 1-on-1 play situations when the result was tied.

\section{Acknowledgments}

This study did not use sources of funding.

\section{Conflict of interest}

Authors declare no conflict of interest.

\section{References}

1. Szwarc A, Kromke K, Lipińska P. The efficiency of football players in one against one game in the aspect of situational factors of a sports fight. Arch Budo, 2012;8(2):91- 102. https://doi.org/10.12659/AOB.882963

2. Sgrò F, Aiello F, Casella A, Lipoma M. The effects of match-playing aspects and situational variables on achieving score-box possessions in Euro 2012 Football Championship. J Hum Sport Exerc, 2017;12. https://doi.org/10.14198/jhse.2017.121.05

3. Taylor JB, Mellalieu SD, James N, Shearer DA. The influence of match location, quality of opposition, and match status on technical performance in professional association football. $J$ Sports Sci, 2008;26(9):885-95. https://doi.org/10.1080/02640410701836887

4. Almeida CH, Ferreira AP, Volossovitch A. Effects of Match Location, Match Status and Quality of Opposition on Regaining Possession in UEFA Champions League. J Hum Kinet, 2014;41:203-14. https://doi.org/10.2478/hukin-2014-0048

5. Andersson H, Ekblom B, Krustrup P. Elite football on artificial turf versus natural grass: Movement patterns, technical standards, and player impressions. $J$ Sports Sci, 200815;26(2):113-22. https://doi.org/10.1080/02640410701422076

6. Dellal A, Chamari K, Wong DP, Ahmaidi S, Keller D,
Barros R, et al. Comparison of physical and technical performance in European soccer match-play: FA Premier League and La Liga. Eur J Sport Sci, 2011;11(1):51-9. https://doi.org/10.1080/17461391.2010.481334

7. Lago-Ballesteros J, Lago-Peñas C, Rey E. The effect of playing tactics and situational variables on achieving score-box possessions in a professional soccer team. $J$ Sports Sci, 2012;30(14):1455- 61. https://doi.org/10.1080/02640414.2012.712715

8. Lago-Peñas C, Dellal A. Ball Possession Strategies in Elite Soccer According to the Evolution of the Match-Score: the Influence of Situational Variables. $J$ Hum Kinet, 2010;30;25(1):93-100. https://doi.org/10.2478/v10078-010-0036-Z

9. Liu H, Gomez M-Á, Lago-Peñas C, Sampaio J. Match statistics related to winning in the group stage of 2014 Brazil FIFA World Cup. J Sports Sci, 201521;33(12):1205-13. https://doi.org/10.1080/02640414.2015.1022578

10. Sarmento H, Marcelino R, Anguera MT, CampaniÇo J, Matos N, LeitÃo JC. Match analysis in football: a systematic review. $J$ Sports Sci, 2014;32(20):1831-43. https://doi.org/10.1080/02640414.2014.898852

11.Ávila-Moreno FM, Chirosa-Ríos LJ, Ureña-Espá A, Lozano-Jarque D, Ulloa-Díaz D. Evaluation of tactical performance in invasion team sports: a systematic review. Int J Perform Anal Sport, 2018;18(2):195-216. 
https://doi.org/10.1080/24748668.2018.1460054

12.Castellano J, Casamichana D, Lago C. The Use of Match Statistics that Discriminate Between Successful and UnsuccessfulSoccerTeams.JHumKinet, 20121;31(1):137-47. https://doi.org/10.2478/v10078-012-0015-7

13.Dellal A, Wong DP, Moalla W, Chamari K. Physical and technical activity of soccer players in the French First League - with special reference to their playing position. Int Sport $J$, 2010;11(2):278-90.

14.Liu H, Yi Q, Giménez J-V, Gómez M-A, LagoPeñas C. Performance profiles of football teams in the UEFA Champions League considering situational efficiency. Int J Perform Anal Sport, 2015;15(1):371-90. https://doi.org/10.1080/24748668.2015.11868799

15.Shafizadeh M, Davids K, Correia V, Wheat J, Hizan H. Informational constraints on interceptive actions of elite football goalkeepers in 1v1 dyads during competitive performance. $J$ Sports Sci, 2016;34(17):1596-601. https://doi.org/10.1080/02640414.2015.1125011

16.Szwarc A, Kromke K, Radzimiński Ł， Jastrzębski Z. Efficiency of 1-on-1 play situations for highlevel soccer players during theworld and European championships in relation to position on the pitch and match time. Int J Sport Sci Coach, 2017;12(4):495-503. https://doi.org/10.1177/1747954117717890

17.Loy R. Systematische Spielbeobachtung im Fußball. Leistungssport. 1995;3:15-20.

18. Armatas V, Yiannakos A, Sileloglou P. Relationship between time and goal scoring in soccer games: Analysis of three World Cups. Int J Perform Anal Sport, 2007;7(2):48-58. https://doi.org/10.1080/24748668.2007.11868396

19.Njororai WWS. Analysis of goals scored in the 2010 world cup soccer tournament held in South Africa. J Phys Educ Sport, 2013;13(1):6-13.

20.Harper LD, West DJ, Stevenson E, Russell M. Technical Performance Reduces during the Extra-Time Period of Professional Soccer Match-Play. Sandbakk O, editor. PLoS One, 2014 Oct 24;9(10):e110995. https://doi.org/10.1371/journal.pone.0110995

21.Zhao Y-Q, Zhang H. Analysis of goals in the English Premier League. Int J Perform Anal Sport, 2019;19(5):820-31. https://doi.org/10.1080/24748668.2019.1661613

22.Shafizadeh M, Taylor M, Peñas CL. Performance Consistency of International Soccer Teams in Euro 2012: a Time Series Analysis. J Hum Kinet, 2013;38:213-26. https://doi.org/10.2478/hukin-2013-0061

23. Vogelbein M, Nopp S, Hökelmann A. Defensive transition in soccer - are prompt possession regains a measure of success? A quantitative analysis of German FußballBundesliga 2010/2011. J Sports Sci, 2014;32(11):1076-83. https://doi.org/10.1080/02640414.2013.879671

24.Harrop K, Nevill A. Performance indicators that predict success in an English professional League One soccer team. Int $J$ Perform Anal Sport, 2014;14(3):907-20. https://doi.org/10.1080/24748668.2014.11868767

25.Collet $\mathrm{C}$. The possession game? A comparative analysis of ball retention and team success in European and international football, 2007-2010. J Sports Sci, 2013;31(2):123-36. https://doi.org/10.1080/02640414.2012.727455

26.O'Donoghue P. Factors influencing the accuracy of predictions of the 2014 FIFA World Cup. Int J Comput Sci Sport, 2014;13(2):32-49.

27.Barreira D, Garganta J, Guimarães P, Machado J, Anguera MT. Ball recovery patterns as a performance indicator in elite soccer. Proc Inst Mech Eng Part P J Sport Eng Technol, 2014;228(1):61-72. https://doi.org/10.1177/1754337113493083

28.Link D, Hoernig M. Individual ball possession in soccer. PLoS One, 2017;12(7):e0179953. https://doi.org/10.1371/journal.pone.0179953

29.Gómez MA, Gómez-Lopez M, Lago C, Sampaio J. Effects of game location and final outcome on game-related statistics in each zone of the pitch in professional football. Eur J Sport Sci, 2012;12(5):393-8. https://doi.org/10.1080/17461391.2011.566373

30.Wallace JL, Norton KI. Evolution of World Cup soccer final games 1966-2010: Game structure, speed and play patterns. $J$ Sci Med Sport, 2014;17(2):223-8. https://doi.org/10.1016/j.jsams.2013.03.016

31.Szwarc A, Dolański B. The soccer player's activity under aspect of the alteration of content results. Pedagog Psychol Medical-Biological Probl Phys Train Sport, 2009;9:200-5.

32.Lago-Peñas C, Gómez-López M. How Important is it to Score a Goal? The Influence of the Scoreline on Match Performance in Elite Soccer. Percept Mot Skills, 2014;119(3):774-84. https://doi.org/10.2466/23.27.PMS.119c32z1 


\section{Information about the authors:}

Andrzej Szwarc; https://orcid.org/0000-0003-1959-3902; andrzej.szwarc@awf.gda.pl; Department of Sport, Gdansk University of Physical Education and Sport; Gdansk, Poland.

Krzysztof Kromke; https://orcid.org/0000-0001-9059-6204; christoph@kromke.info; St. Augustinusschule; Ettlinen, Germany.

Aleksander Stuła; https://orcid.org/0000-0002-3940-9781; a.stula@po.opole.pl; Department of Physical Education and Physiotherapy, The Opole University of Technology; Opole, Poland.

Bartosz Dolański; https://orcid.org/0000-0002-1844-2160; bartosz.dolanski@awf.gda.pl; Department of Sport, Gdansk University of Physical Education and Sport; Gdansk, Poland.

Mateusz Sitek; (Corresponding author); https://orcid.org/0000-0002-8485-231X; mateusz.sitek16@gmail.com; Department of Sport, Gdansk University of Physical Education and Sport; Gdansk, Poland.

\section{Cite this article as:}

Andrzej Szwarc, Krzysztof Kromke, Aleksander Stuła, Bartosz Dolański, Mateusz Sitek. Efficiency of one-on-one play situations of Polish football players and their opponents during European Championships in relation to the playing area, current result and match. Physical Education of Students, 2020;24(3):174-185. https://doi.org/10.15561/20755279.2020.0308

This is an Open Access article distributed under the terms of the Creative Commons Attribution License, which permits unrestricted use, distribution, and reproduction in any medium, provided the original work is properly cited http://creativecommons.org/licenses/by/4.0/deed.en

Received: 04.04.2020

Accepted: 11.05.2020; Published: 30.06.2020 